\title{
Individual Risk Factors for PTSD in Adolescents from the 2010 Earthquake in Yushu: The Predictor Effect of Rumination
}

\section{Yuchang Jin* and Guan Wang}

College of Teacher Education, Sichuan Normal University, Chengdu, 610066, China

*Corresponding author: Yuchang Jin, Sichuan Normal University, No.5, Jinan Road, Jinjiang district, Chengdu, Sichuan, 610066 P.R. China,Tel: +86 28 62373987; Email: Jinyuchang@gmail.com

Received Date: July 28, 2014, Accepted Date: September 15, 2014, Published Date: September 22, 2014

Copyright: (c) 2014, Yuchang Jin et al., This is an open-access article distributed under the terms of the Creative Commons Attribution License, which permits unrestricted use, distribution, and reproduction in any medium, provided the original author and source are credited.

\begin{abstract}
Background: Prevention of psychology about adolescent after earthquake in developing country has become more and more important. This study was undertaken three years after the Yushu earthquake in post-traumatic stress disorder (PTSD). The survey was conveyed in Yushu Tibetan autonomous regions Ethnic School and the number of the participants was about one thousand. The focus of our study is individual risk factors for PTSD.

Method: T-test and chi-square test are mainly used to examine the correlation. In particularly, comprehend multiple regressions.

Results: Although correlation analysis indicated that there is not any significant different on gender and PTSD in these adolescents, ethnicity dose not also play a significant role in PTSD. We find a positive correlation between grade and PTSD. Family type is important factors for PTSD too. The similar result is also supported by Chi square test. Deliberation---a subtype of rumination could predict the PTSD effectively.

Conclusion: This study demonstrated the prevalence of PTSD was low among Tibetan adolescent. Deliberate-a subtype of rumination might have severe impact to the course of PTSD and should therefore be carefully diagnosed and treated early in the course of illness
\end{abstract}

Keywords: Posttraumatic stress disorder; Rumination; Adolescents; Earthquake

\section{Introduction}

Most earthquakes which occur in developing countries bring enormous trauma and stress. On April 14, 2010, a magnitude 7.1 earthquake occurred in China's Qinghai Yushu region, which is located in the Qinghai-Tibet Plateau. The Yushu earthquake caused 2,698 deaths with a further 270 missing, over 12, 000 injuries, and left over 100,000 people homeless causing a serious impact on the local people's lives.

The immense physical devastation and emotional suffering, coupled with a great feeling of loss resulted in severe mental health issues for survivors of the earthquake [1]. Experiencing an earthquake has been associated with PTSD. Symptoms of PTSD include intrusion, avoidance and hyper arousal. Date suggest that PTSD may be the prevalent mental disorder after exposure to earthquake. Although many researchers have studied PTSD among survivors of earthquake, adolescents go through many physical and psychological changes. PTSD in both children and adolescents differs from that in adults [2]. Especially, there is little study among adolescent of minority. This was true for the adolescents of Tibetan who were the focus of this study. Neuropsychological assessments have revealed that children and adolescents suffering from PTSD have significant problems [3]. Some people even believe that the DSM (Diagnostic and Statistical Manual of Mental Disorders) criteria for PTSD should be modified for younger people, such as in a lowering of the threshold for avoidance behavior or considering variants of the disorder [4]. Therefore, the disaster response of adolescents is worthy of attention.

According to previous studies, the prevalence of PTSD reported in victims after disasters ranges from between $3 \%$ to $87 \%[5,6]$. In general, mental health outcomes following an earthquake are determined by a complex set of factors [1], such as gender, grade, family type, ethnicity, religion, injuries sustained in the earthquake, and social support $[7,8]$. The variability in the range of PTSD rates in these studies may be explained by the differences in the sampling methods, the extent of devastation caused by the earthquake, the time lapse between the onset of the disaster and data collection $[7,9]$.

Except for the frequently reported individual risk factors, rumination has also been recognized as a representative variable. Although some researchers have presented rumination as a stable maladaptive coping strategy aimed at changing the situation or relieving distress [10], rumination as a moderator variable has rarely been considered in adolescent samples. A recent comprehensive review highlighted that rumination could be characterized as constructive and productive or negative and unconstructive [11]. Some research has found that rumination significantly predicted PTSD and depression at 6 months over and above what could be predicted from initial symptom levels [12]. Burwell and Shirk argued that brooding, a subtype of rumination, could predict the development of depressive symptoms over time [13].

Moreover, many previous PTSD studies have primarily dealt with only the short-term impact of the earthquake event [14,15], but have not investigated the long-term development of PTSD among 
adolescents in severely damaged areas, especially those of Tibetan ethnicity.

The present study aimed to estimate a relationship between PTSD and individual risk factors in adolescents of Tibetan three years after the earthquake event by looking at the effects of gender, grade, family status, ethnicity, religion, and rumination. This study may be useful for directing and strengthening disaster-related mental health services, as well as providing information on the psychological impact of the earthquake on the Tibetan ethnicity in China.

\section{Methods}

\section{Procedure and participants}

The study was conducted three years after the earthquake from April, 14th, 2013 to April, 26th, 2013. Participants came from Yushu national school, except for the limited conditions, such as this school was boarding and these students were basically living in school, a large of number adolescents and their characteristics are comparable in the school were also reasons. All participants we sampled, most of who were of Tibetan ethnicity of Yushu national school, which is located in the center of Yushu city and has a primary school, middle school and high school. From June 2010 to July 2012, the members of our team, who were working as psychological assistants, approached the participants from the Yushu national high school. Participants were selected using cluster a sampling strategy, were assured of their confidentiality and were informed that they could withdraw at any time. Participants were given information orally about the study's purpose and oral consents were obtained before investigation. All tests used consistent instructions. Although most students were Tibetan, they had been educated in both Chinese and Tibetan, so there were no translation issues. One thousand questionnaires were handed out, with ninety-seven questionnaires not being completed, and fifty-three not filled out correctly, so these were eliminated, leaving 850 valid samples, a response rate of $85 \%$. The study was designed in accordance with the tenets of the Declaration of Helsinki and was approved by the ethics committee of Sichuan University. The investigation complied with the principle of voluntarism.

\section{Measures}

The self-report questionnaire covered items on demographic characteristics, PTSD and rumination. Basic demographic information was elicited using a questionnaire which included gender, grade, ethnicity, and family type. Posttraumatic stress disorder (PTSD) was assessed using the PTSD Check List, Civilian Version (PCL-C). The scale has 17 questions in which respondents are asked how often they had been bothered by each symptom in the past month on a 1 (not at all) to 5 (extremely) Likert-type scale, for a total range of 17 to 85 . Generally, reports of the PCL's reliability and validity have been positive. The internal reliabilities of the three subscales on PCL were . 83,81 , and 80 , respectively. Two to three days test-retest reliability on Vietnam veterans was found to be .96 in one study and .66 for a 2 week test-retest interval for psychiatric inpatients [16]. The Chinese version of the PCL has been adapted through a two-stage process of translation and back translation [17]. Its applicability in adolescents has been previously demonstrated by studies with both Western and Chinese samples [18-21]. The internal consistency of the PCL-C at the two time points in the current sample was .87 at the baseline and .88 at the follow-up, and inter-rater reliability was .80 .
The function of rumination, or repetitive thought, is thought to be of particular importance in the PTSD. A study hypothesized that there was a link between deliberate ruminative thinking and self-system variables and the accompanying study showed this to be the case [22]. Some research has reported a significant relationship between rumination and children's competency beliefs [23], with the rumination being assessed using the Global Ruminative Response Scale (RRS) [24]. Cryder and others have divided rumination into two dimensions of intrusion and deliberation [23], while other research has called these brooding and self-reflection [13]. Regardless of the terminology, RRS measures intrusive behavior (2 items; e.g., "I think about it when I don't mean to") and deliberate rumination, (3 items; e.g., "Sometimes I think about it to try to figure out why things like that happen"). Adolescents responded using a scale from 1 (not at all true for me) to 5 (very true for me). Reliability of the scale was $\alpha=.80$ and there was good validity. The two factors were computed using a mean score across the RRS items.

\section{Statistical analysis}

We used SPSS 18 for data analysis. First of all, the descriptive statistics were presented from the demographic variables. Then the PCL-C scores of the 850 subjects exposed to Yushu earthquake three years after the earthquake event were analyzed and the SSR scores calculated.

\section{Results}

\section{Demographic characteristics}

The sample included 382 boys (44.8\%) and 468 girls (55.2\%), of which 833 were Tibetan (98\%) and 17 were Han (2\%). The sample was made up of 291 middle school students (34.2\%) and 559 high school students $(65.8 \%)$, of whom $68(8 \%)$ came from two generation family setups (nuclear) and 782(92\%) came from three generation or more family setups (joint family). A two generation or nuclear family setup refers to families which have only two generations, the parents and their son or daughter. Joint family setups include three generations or more living together. The age range of the sample was $12-20$ years, with a mean of $15.73 \pm 1.82$ years. The PTSD prevalence found in the study was $8.94 \%$. The detailed data for these demographic variables is shown in Table 1

\section{PTSD Score for individual risk factors}

As shown in Table 2, the PTSD average for adolescents from joint family setups was found to be 32.29 , while the average for the nuclear family was 51.94. Further, it was found that the school grade level showed significant PTSD differences for the middle school and high school students, where the PTSD for middle school students was, on average, lower than that for high school students. The grade rather than the age was investigated as Chinese high school and middle school are both of three years duration, so those participants in high school had been middle school students at the time of the earthquake event and had just entered puberty, while the middle school participants has been primary school pupils and had not entered puberty. Therefore, through the analysis of the grade, we were able to determine the effect of puberty. In terms of gender, the table shows that there were no significant differences between the PTSD of male and female participants. 
Citation: Jin Y, Wang G (2014) Individual Risk Factors for PTSD in Adolescents from the 2010 Earthquake in Yushu: The Predictor Effect of

Page 3 of 6

\begin{tabular}{|c|c|c|c|c|c|}
\hline variables & & $\mathbf{n}$ & $\%$ & Subjects with PTSD (n) & Subjects without PTSD (n) \\
\hline \multicolumn{6}{|c|}{ Family type } \\
\hline & $\begin{array}{l}\text { Unclear } \\
\text { family }\end{array}$ & 68 & 8 & 46 & 22 \\
\hline & $\begin{array}{l}\text { Joint } \\
\text { family }\end{array}$ & 782 & 92 & 30 & 752 \\
\hline \multicolumn{6}{|l|}{ grade } \\
\hline & Middle school & 291 & 34.2 & 17 & 274 \\
\hline & High school & 559 & 65.8 & 59 & 500 \\
\hline \multicolumn{6}{|c|}{ Ethnicity(Religion) } \\
\hline & Tibetan & 833 & 98 & 71 & 762 \\
\hline & Han & 17 & 2 & 2 & 15 \\
\hline \multicolumn{6}{|l|}{ Gender } \\
\hline & Male & 382 & 44.9 & 31 & 351 \\
\hline & Female & 468 & 55.1 & 45 & 420 \\
\hline
\end{tabular}

Table 1: Demographic characteristic variable of the participant, ${ }^{*} \mathrm{p}<0.05$; ${ }^{* *} \mathrm{p}<0.01 ;{ }^{* *} \mathrm{p}<0.001$

\begin{tabular}{|l|l|l|l|}
\hline Gender & M & SD & $\mathbf{p}$ \\
\hline male & 33.97 & 10.55 & .805 \\
\hline female & 33.78 & 11.29 & \\
\hline Grade & & & \\
\hline middle school & 32.22 & 10.19 & $.002^{*}$ \\
\hline high school & 34.72 & 11.26 & \\
\hline Ethnicity & & & \\
\hline Tibetan & 33.93 & 10.87 & .248 \\
\hline Han & 30.82 & 14.69 & \\
\hline Family type & & & \\
\hline Joint family & 32.29 & 9.81 & $.000^{* * *}$ \\
\hline Unclear family & 51.94 & 6.30 & \\
\hline
\end{tabular}

Table 2: PTSD scores three years after Yushu earthquake, ${ }^{*} \mathrm{p}<0.05 ;{ }^{* *} \mathrm{p}<0.01 ;{ }^{* *} \mathrm{p}<0.001$

Using a chi square test, we reconfirmed the conclusions in Table 2. In Table 3, it can be seen that the actual observation and theoretical frequency distribution of the PTSD for gender show no significant differences. However, grade, and family type were found to have a large influence on the level of PTSD. Table 3 shows the estimated percentage of subjects who met DSM-IV criteria for PTSD three years after the earthquake event. Among our sample, while gender was not found to be associated significantly with PTSD, PTSD was found to be significantly more prevalent in high school students than middle school students $(10.6 \%$ vs. $5.8 \%, \mathrm{P}<.05)$. Ethnicity did not appear to play a role in the rate of PTSD as both Tibetan and Han participants had similar profiles, but family type showed significant influence for PTSD prevalence, with students living in nuclear families being more likely to suffer PTSD than those living in joint family setups.

\begin{tabular}{|c|c|c|c|c|}
\hline Variables & $\begin{array}{l}\text { Subjects with } \\
\text { PTSD (n) }\end{array}$ & $\begin{array}{l}\text { Subjects } \\
\text { without PTSD } \\
\text { (n) }\end{array}$ & $\begin{array}{l}\text { OR } \\
\qquad(95 \% \mathrm{Cl})\end{array}$ & \\
\hline \multicolumn{5}{|l|}{ gender } \\
\hline Male & 31 & 350 & 1 & 0.446 \\
\hline Female & 45 & 424 & $\begin{array}{l}1.205 \\
746-1.944)\end{array}$ & \\
\hline \multicolumn{5}{|l|}{ Grade } \\
\hline Middle school & 17 & 274 & & $.022^{*}$ \\
\hline High school & 59 & 500 & 1 & \\
\hline Ethnicity & & & $\begin{array}{l}1.902(1.087- \\
3.327)\end{array}$ & \\
\hline Tibetan & 71 & 762 & & .0680 \\
\hline Han & 2 & 15 & 1 & \\
\hline \multicolumn{5}{|l|}{ Family type } \\
\hline Unclear family & 46 & 22 & $\begin{array}{l}1.368(. \\
307-6.096)\end{array}$ & $.000^{* *}$ \\
\hline Joint family & 20 & 762 & $\begin{array}{l}58.113(30.8 \\
21-109.575)\end{array}$ & \\
\hline
\end{tabular}

Table 3: Comparison of PTSD risk factors, ${ }^{*} \mathrm{p}<0.05 ;{ }^{* *} \mathrm{p}<0.01$; ${ }^{* * *} \mathrm{p}<0.001 ; \mathrm{OR}=$ odd ratios; $\mathrm{CI}=$ confidence interval

\section{Multiple regression analysis}

Based on the data of PTSD patients, the multivariate logistic regression analysis has been shown in Table 4 . All risk factors included gender, grade, ethnicity; family type and rumination were entered into the multiple logistic regression analysis. The deliberation-rumination subtype, unclear family and High school (independent variables) explained the prevalence of PTSD (the dependent variable). Result 
indicated gender and ethnicity were not significant associated with PTSD.

The logistic regression analysis was conducted with the prevalence of PTSD as the dependent variable, and result indicated that deliberation, unclear family and high school are predictive risk factors.

\begin{tabular}{|l|l|l|l|l|l|l|l|}
\hline variable & $\mathbf{b}$ & $\mathbf{S E}$ & Wals & $\mathbf{p}$ & OR & \multicolumn{2}{|l|}{$\mathbf{9 5 \%} \mathbf{C l}$} \\
\hline Female & .845 & .375 & 5.079 & $.046^{*}$ & 2.329 & 1.116 & 4.859 \\
\hline High school & .639 & .410 & 2.431 & $.039^{*}$ & 1.894 & .849 & 4.229 \\
\hline Tibetan & 1.006 & 1.286 & .612 & .434 & 2.734 & .220 & 33.976 \\
\hline Deliberation & -.924 & .115 & $\begin{array}{l}64.75 \\
3\end{array}$ & $.000^{\star \star *}$ & .397 & .317 & .497 \\
\hline Unclear family & 3.276 & .387 & $\begin{array}{l}71.69 \\
9\end{array}$ & $.000^{* * *}$ & 6.475 & 2.402 & 9.517 \\
\hline Constant & -.676 & .957 & .498 & .480 & .509 & \multicolumn{3}{|l}{} \\
\hline
\end{tabular}

Table 4: Multivariate logistic regression analysis of risk factors, ${ }^{\star} \mathrm{p}<0.05^{\star *} \mathrm{p}<0.01 ;{ }^{* *} \mathrm{p}<0.001 ; \mathrm{OR}=$ odd ratios; $\mathrm{CI}=$ confidence interval

\section{Discussion}

The study analyzed the prevalence of and the individual risk factors for PTSD in Yushu national high school students. Yushu belongs to the Tibetan Plateau District and has harsh natural conditions. After the earthquake event, there was a severe lack of material supplies as the earthquake had destroyed many homes and buildings as well as causing significant infrastructure damage.

The rate of PTSD in participants 3 years after the earthquake event was found to be $8.9 \%$. There have been a few studies that have investigated posttraumatic symptoms among earthquake victims. The rate of PTSD was found to be $23 \% 13$ months after the 1998 southern Turkish earthquake [25]. Chen and his colleagues found that $20.9 \%$ subjects met the criteria for PTSD 2 years after the 1999 Taiwan earthquake [26]. In a study of 683 individuals conducted 3 years after the 1999 Marmara earthquake, the PTSD prevalence was found to be $19.2 \%$ [27]. These differences between the various studies could be attributed to the variability in earthquake intensities, the research designs, the sample types and the time elapsed since the earthquake event. The low prevalence of PTSD found in our adolescent sample could be because the school had been moved out of the affected area after the earthquake to Juyuan Middle School in Dujiangyan, Sichuan province, so, although the participants has experienced a major disaster event, they had been living in a new and safe environment, resulting in a reduction in trauma exposure. Further, earthquake intensity may also be a factor. In the 2008 Wenchuan earthquake, the intensity reached 8.0 on the Richter scale, but the Yushu earthquake was only 7.1, which may also have contributed to the lower rate of PTSD shown in the sample.

From Table 2, we could infer that the reason high school students appeared to experience a higher level of PTSD is that high school students are more able to cognitively and emotionally process traumatic experiences than younger students, so this may have meant that they had experienced the trauma more deeply. However, the age of the participants at the time of the earthquake needs to be taken into account, as those participants from the middle school had not yet entered puberty at the time of the event. Therefore, for children, the impact of the disaster was possibly smaller than on those who were adolescents at the time. Another possibility is that at the time of the event the adolescents (the high school students in our study) had begun to explore their self-identity and they might have had identity confusion, which some researchers have suggested could lead to mental disorders [28], but further evidence is necessary regarding this point of view.

In this region, gender and PTSD scores had no significant differences, which is inconsistent with some existing research [29-31]. However, most participants were Tibetan, so were also advocates of Tibetan Buddhism. In this culture, girls and boys have similar responsibilities and obligations and because of the region's natural conditions and the harsh environment, they tend to have tough optimistic characters which may explain the unexpected results.

A majority of the participants living in joint family setups (92\%) reported a lower PTSD score that those living in nuclear families. This could be explained as those who lived in joint family setups had access to greater social support, which includes religious support as $99 \%$ of Tibetans believe in Tibetan Buddhism and thus have faith in reincarnation. Therefore, when a disaster occurs, they are able to better cope with the resulting trauma. It has been reported that positive reinterpretation and acceptance are significantly related to the cognitive/affective and social subscales of the Stress-Related Growth Scale for Adolescents (SRGS-A) [32], and these factors are very important for recovery from psychological trauma. Further, the provision of outside support from volunteer organizations and psychological volunteers may have significantly inhibited the occurrence of PTSD after the earthquake event. Another important consideration is that most of the participants had been moved to areas with better economic conditions to start learning again after the earthquake event, effectively removing them from the damaged areas. Also, while at these off-site areas, there were professional psychologists to assist these students. Thus, psychological intervention may have played an important role in trauma recovery.

Some studies have explored the relationship between rumination and PTG. However, as a mediator of the relationship between trauma and PTG, rumination can also be used to analyze the prevalence of PTSD. Our results indicated that deliberation, a subtype of rumination, could predict the PTSD level. We found that there was a negative correlation between deliberation and the PTSD level. This could have assisted in dealing with any psychological disorders and thus reduced the incidence of PTSD. The results of this study indicated that rumination in the form of active deliberation about emotions predicted the development of PTSD in adolescents.

\section{Conclusion and Limitations}

In this study, we mainly analyzed the individual risk factors of gender, grade, and social support, as well as the role of rumination. Gender as a major risk factor did not show any significant PTSD differences, but the results for these individual risk factors have not always been consistent. In other words, the risk factors do not always predict equally well [33]. However, the data provided valuable information about the prevalence of PTSD three years after a disastrous earthquake event in Tibetan adolescents. Participants who had reached puberty, came from a nuclear family, and indulged in rumination were found to be significant risk factors for the development of PTSD in the aftermath of the disaster, especially if the disaster has been introspected by these adolescent initiatively. 
Moreover, unlike the earthquake of Wenchuan, governments transfer these students timely, and avoid them exposing in earthquake scene continually. So, low exposure level has an important effect to the prevalence of PTSD. This study may be useful for strengthening, directing and evaluating mental health needs, as well as providing information on the psychological impact of the earthquake on this particular ethnic group in China.

Some limitations to this study should be noted. A self-report of PTSD symptoms may be considered less accurate. Because the sample size was large, volunteers adopted self-report instruments according to the local conditions. The most important limitation was in the use of these self-report instruments, instead of using the ratings of a clinician to detect PTSD symptoms. Secondly, the subjects were chosen from a national School, in which the participants were mainly Tibetan adolescents, so cultural differences were not significant. Whether the cultural differences between the Han and the Tibetans is an important factor for PTSD incidence will be looked at more closely in the future. Thirdly, this cross-sectional survey was conducted three years after earthquake, which may lose sight of the fact that Children's own psychological adjustment and long-term health service utilization to effect the incidence of the PTSD (Figure 1). In the future, more attention needs to be paid to longitudinal studies. Finally, while some studies have shown that there is a genetic vulnerability associated with PTSD [34,35], future studies should extract parts of the typical features of the sample, and use a more comprehensive and accurate method, such as a gene analysis, to explore the individual risk factors.

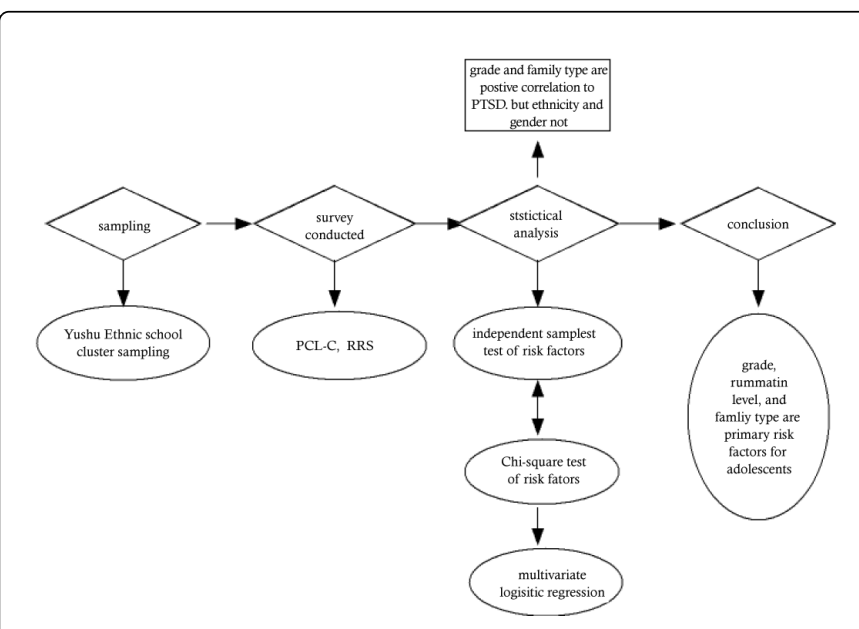

Figure 1: The flow process chart of the epidemiological survey in the Yushu earthquake

\section{Acknowledgments}

The research is supported by National Social Science Foundation of China (Grant No. 12XSH019), the ministry of Education of Humanities and Social Science Project of China (Grant No. 12YJA190009). We appreciated these support both in finance and in spirit.

\section{References}

1. Chen G, ShenH (2012) A cross-sectional study on posttraumatic stress disorder among elderly Qiang citizens 3 years after the Wenchuan earthquake in China. Canadian journal of psychiatry. Revue canadienne de psychiatrie 57: 547-553.

2. Huemer J, Erhart F, Steiner H (2010) Posttraumatic stress disorder in children and adolescents: a review of psychopharmacological treatment. Child Psychiatry \& Human Development 41: 624-640.

3. Turley MR, Obrzut JE (2012) Neuropsychological effects of posttraumatic stress disorder in children and adolescents. Canadian Journal of School Psychology 27: 166-182.

4. Portnova A (2007) Typology of post-traumatic stress disorder in children and adolescents. Neuroscience and Behavioral Physiology 37: 7-11.

5. GroomeD, Sourei A (2004) Posttraumatic stress disorder and anxiety symptoms in children exposed to the 1999 Greek earthquake. British Journal of Psychology 95: 387-397.

6. Santiago PN, Ursano RJ, Gray CL, Pynoos RS, Spiegel D, et al. (2013) A systematic review of PTSD prevalence and trajectories in DSM-5 defined trauma exposed populations: Intentional and non-intentional traumatic events. PloS one 8: e59236.

7. Grubaugh AL, Zinzow H M, PaulL, Egede L E, Frueh BC (2011) Trauma exposure and posttraumatic stress disorder in adults with severe mental illness: a critical review. Clinical psychology review 31: 883-899.

8. Baranyi A, LeithgöbO, KreinerB, TanzerK, EhrlichG, et al. (2010) Relationship between posttraumatic stress disorder, quality of life, social support, and affective and dissociative status in severely injured accident victims 12 months after trauma. Psychosomatics 51: 237-247.

9. Karl A, Werner A (2010) The use of proton magnetic resonance spectroscopy in PTSD researchmeta-analyses of findings and methodological review. Neuroscience \& Biobehavioral Reviews 34: 7-22.

10. Nolen-Hoeksema S (1991) Responses to depression and their effects on the duration of depressive episodes. Journal of abnormal psychology 100(4): 569.

11. Watkins ER (2008) Constructive and unconstructive repetitive thought. Psychological bulletin 134: 163.

12. Ehring T, Frank S, Ehlers A (2008) The role of rumination and reduced concreteness in the maintenance of posttraumatic stress disorder and depression following trauma. Cognitive therapy and research 32: 488-506.

13. Burwell RA, Shirk SR (2007) Subtypes of rumination in adolescence: Associations between brooding, reflection, depressive symptoms, and coping. Journal of Clinical Child and Adolescent Psychology 36: 56-65.

14. Kun P, Chen X, Han S, Gong X, Chen M, et al.(2009) Prevalence of posttraumatic stress disorder in Sichuan Province, China after the 2008 Wenchuan earthquake. Public Health123: 703-707.

15. Zhang Y, Ho SM (2011) Risk factors of posttraumatic stress disorder among survivors after the 512 Wenchuan earthquake in China. PloS one 6: e22371.

16. McDonald SD, Calhoun PS (2010) The diagnostic accuracy of the PTSD Checklist: A critical review. Clinical psychology review 30: 976-987.

17. Wu K, Chan S, Yiu V (2008) Psychometric properties and confirmatory factor analysis of the posttraumatic stress disorder checklist for Chinese survivors of road traffic accidents. Hong Kong Journal of Psychiatry 18: 144-155.

18. Barnes VA, Treiber FA, Ludwig DA (2005) African-American adolescents' stress responses after the 9/11/01 terrorist attacks. Journal of adolescent health 36: 201-207.

19. Wang L, Long D, Li Z, Armour C (2011) Posttraumatic stress disorder symptom structure in Chinese adolescents exposed to a deadly earthquake. Journal of abnormal child psychology 39: 749-758.

20. Wang L, Zhang J, Shi Z, Zhou M, Li Z, et al. (2011) Comparing alternative factor models of PTSD symptoms across earthquake victims and violent riot witnesses in China: Evidence for a five-factor model proposed by Elhai et al. J anxiety disord 25: 771-776.

21. Wang M, Dai X, Wan J (2009) Factor structure of PTSD Checklist: A confirmatory factor analysis study in adolescents from earthquake region. Chinese Journal of Clinical Psychology 17: 420-423.

22. Kilmer R P (2006) Resilience and Posttraumatic Growth in Children. 
Citation: Jin Y, Wang G (2014) Individual Risk Factors for PTSD in Adolescents from the 2010 Earthquake in Yushu: The Predictor Effect of Rumination. J Psychiatry 17: 1000144. doi:10.4172/2378-5756.1000144

Page 6 of 6

23. Cryder CH, KilmerRP, Tedeschi RG, nCalhoun LG (2006) An exploratory study of posttraumatic growth in children following a natural disaster. American J Orthopsyc 76: 65-69.

24. Calhoun LG, Cann A, Tedeschi RG, McMillan J (2000) A correlational test of the relationship between posttraumatic growth, religion, and cognitive processing. J Trauma Stress13: 521-527.

25. Altindag A, Ozen S (2005) One-year follow-up study of posttraumatic stress disorder among earthquake survivors in Turkey. Compr Psychiatry 46: 328-333.

26. Chen CH, Tan H KL, Liao LR, Chen HH, Chan CC, et al. (2007) Longterm psychological outcome of 1999 Taiwan earthquake survivors: a survey of a high-risk sample with property damage. Comprehensive Psychiatry 48: 269-275.

27. Tural Ü, Coşkun B, Önder E, Çorapçioğlu A, Yildiz M, et al. (2004) Psychological consequences of the 1999 earthquake in Turkey. Journal of Traumatic Stress 17:451-459.

28. Beaumont SL, Zukanovic R (2005) Identity Development in Men and its Relation to Psychosocial Distress and Self-Worth. Canadian Journal of Behavioural Science/Revue canadienne des sciences du comportement 37: 70 .

29. Felmingham K, Williams LM, Kemp AH, Liddell B, Falconer E, et al. (2010) Neural responses to masked fear faces: sex differences and trauma exposure in posttraumatic stress disorder. Journal of abnormal psychology 119: 241 .

30. Lilly MM, Valdez CE (2012) Interpersonal trauma and PTSD: The roles of gender and a lifespan perspective in predicting risk. Psychological Trauma: Theory, Research, Practice and Policy 4: 140.

31. Tolin DF, Foa EB (2006) Sex differences in trauma and posttraumatic stress disorder: a quantitative review of 25 years of research. Psychological bulletin 132: 959.

32. Vaughn AA, Roesch SC, Aldridge AA (2009) Stress-Related Growth in Racial/Ethnic Minority Adolescents Measurement Structure and Validity. Educational and Psychological Measurement 69: 131-145.

33. Brewin CR, Andrews B, ValentineJ D (2000) Meta-analysis of risk factors for posttraumatic stress disorder in trauma-exposed adults. J consult clin psychol 68: 748 .

34. Skelton K, Ressler KJ, Norrholm SD, Jovanovic T, Bradley-Davino B (2012) PTSD and gene variants: new pathways and new thinking. Neuropharmacology 62: 628-637.

35. Wolf EJ, Miller MW, Krueger RF, Lyons MJ, Tsuang MT, et al. (2010) Posttraumatic stress disorder and the genetic structure of comorbidity. Journal of abnormal psychology 119: 320 